\title{
Commentary
}

\section{Meal deals, combos and bundling: the impact on the nutrition composition of children's meals in restaurants}

\author{
Sue Reeves \\ Health Science Research Centre, University of Roehampton, London, SW15 4JD, UK
}

Submitted 9 December 2019: Accepted 17 December 2019: First published online 30 April 2020

\begin{abstract}
Increased consumption of food outside the home means that the nutritional content of meals served in restaurants now makes a significant contribution to overall diet. Children's menus in restaurants, usually aimed at those aged 10 years and younger, are frequently high in energy, fat, salt, sugar and lack variety. The food and drink on children's menus are often bundled together as a combo or meal deal that may be convenient to order and sometimes, but not always, cheaper. Bundling has the potential to add additional foods that may not have been selected individually thus increasing the amount ordered and consumed. Substituting some meal deal items for healthier options has the potential to make it easier to eat well when eating outside the home and improve dietary intakes. However, the impact of such measures on child health has yet to be fully explored.
\end{abstract}

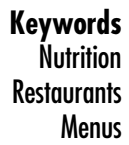

Menus
In the UK, it has been reported that $20 \%$ of children and $27 \%$ of adults eat out at least once every week ${ }^{(1)}$. In the USA, it is stated that $36 \%$ of children aged 2-19 years eat at a fast food restaurant on a typical day ${ }^{(2)}$. Eating in restaurants has now become a regular occurrence rather than an occasional treat ${ }^{(3,4)}$. Given that the incidence of overweight and obesity is still rising ${ }^{(5,6)}$ and levels of obesity disproportionally affect children living in deprived areas ${ }^{(6,7)}$, we need to consider the way unhealthy foods are promoted and how we can facilitate parents to make healthy choices for their children including when eating out of the home.

In the linked paper, Dunn and colleagues ${ }^{(8)}$ consider the Nutrition Composition of Children's Meals in twenty-six large US Chain Restaurants. The authors highlight that not only do restaurants frequently sell unhealthy individual menu items, but they are also often bundled into combinations such as a meal deal that include a main dish, a side order or a dessert and a beverage at a discounted price. Even when healthier sides and beverages are available, they are rarely included as the default meal deal. This paper investigated and found that when the default meals advertised were compared with the minimum and maximum versions that can be chosen, nutrient values differed significantly. For example, they found default meals on average contained $584 \mathrm{kcal}$, whereas the minimum option was $400 \mathrm{kcal}$ and the maximum was $792 \mathrm{kcal}$; similar patterns were seen for fat, salt and sugar. Some items in particular were found to have a salient effect; substituting a beverage for a low energy version or water could reduce energy intakes by on average $100 \mathrm{kcal}$ and sugar by $20 \mathrm{~g}$, and substituting side orders such as French fries resulted in the greatest reductions in fat and salt. They proposed that restaurants could repackage their meal deals by simply substituting healthier items that in most cases, the restaurants already offered; a simple strategy requiring neither reformulation nor investment. Thus, they showed that realistic modifications can significantly alter a meals' nutrient composition and that relatively straightforward changes to beverages and side dishes had the potential to reduce energy, fat, salt and sugar, paving the way for healthier items to be the default options. This confirms the findings from one of our own studies ${ }^{(9)}$ that highlighted the extent to which additional courses and drinks in default meal deals offered on children's menus in restaurants substantially contributed to the energy content of a meal in the UK and Ireland. In particular, by choosing the meal deal option, often seen as more convenient and sometimes, but not always, cheaper, parents are perhaps unknowingly ordering meals that have higher levels of energy, fat, salt and sugar. 
Marketing practices, that often include a toy ${ }^{(10)}$, can persuade increased consumption by using meal bundling and default meals to override individual decisions that encourage customers to buy items together that they may not have chosen if each item were listed separately ${ }^{(11)}$. Bundling may also give the perceived impression of better value for money ${ }^{(12,13)}$. Furthermore in some restaurants, the sheer number of options to choose from can make selecting the healthier choice more complicated than it should be ${ }^{(12)}$. Bundling and meal deals also provide a perception norm ${ }^{(14)}$ and give the notion that the constituent items complement each other ${ }^{(13)}$. This includes desserts and drinks that when included in a meal deal are more likely to be ordered and consumed ${ }^{(15)}$. Thus, bundles increase the purchase of calories which naturally leads to greater consumption ${ }^{(16)}$.

Given that customers often revert to the default menus ${ }^{(15)}$, simple substitutions have the potential to improve the nutrient composition of meals on children's menus in restaurants. There are other studies that have measured the effectiveness of substituting items in different meal deals ${ }^{(17,18)}$. Similarly to the Dunn et al.'s ${ }^{(8)}$ findings, an Australian study found that choosing water rather than a sugar-sweetened beverage could significantly reduce the amount of energy consumed. An American cross-sectional study of 483 restaurant receipts showed that $60 \%$ of beverages purchased were sugar-sweetened, and uncoupling sugary beverages from a meal deal could reduce energy and sugar intakes, since in this study, meals with a non-sugar-sweetened beverage had on average $179 \mathrm{kcal}$ less than meals with a sugar-sweetened beverage ${ }^{(17)}$. Thus, it would appear that eliminating a sugarsweetened beverage offers the easiest way to reduce energy and sugar from a fast food meal. This highlights that a simple move, such as restaurants offering tap water as default, could have a significant effect ${ }^{(7,19)}$. Simple modifications or optimal defaults can nudge choices in a positive direction ${ }^{(15)}$. Bundled meals have been reported as being popular with parents as long as they could choose the individual items that were included ${ }^{(12,20)}$. One qualitative study revealed that parents thought healthier defaults could facilitate ordering and in their view 'help other parents $^{(12)}$. Modifications to children's menus to make them healthier, for example, increasing fruit and vegetable dishes, providing water and the removal of automatic defaults for fries and sugar-sweetened beverages, can result in healthier offerings without removing choice or reducing revenue, so restaurants can remain competitive ${ }^{(21)}$.

In addition to bundling, children's menus are often reported as generally lacking in variety ${ }^{(9)}$ and Hay ${ }^{(22)}$ raised the question why do kid's menus in the UK always have chicken nuggets? A study in Germany also noted that the range of dishes on offer for children is severely restricted and in need of improvement ${ }^{(23)}$. Of course, children are not limited to only choosing from food from the children's menus and can choose from the main restaurant menu; some restaurants may not even have a children's menu. However, an American study showed that $63 \%$ of parents do choose from the children's menu and this was higher in children under the age of 10 years ${ }^{(20)}$. Clearly, restaurants could consider designing their children's menus to include some variety and make the healthy choice the easiest choice $^{(12)}$; however, the full impact of such measures on child health has yet to be explored.

As reported in the linked paper by Dunn and colleagues $^{(8)}$, in the USA, some states have taken legislative action to ensure restaurants provide healthy beverages with children's meals as default; however, less emphasis has been given to other parts of the menu. In the UK, the 2016 sugar levy was a positive step to help improve the quality of beverages on offer; however, it is evident that there is still more work to be done on the menus in many chain restaurants ${ }^{(0,24,25)}$. The second chapter of the UK Childhood Obesity: a plan for action ${ }^{(26)}$ included proposals for several food environment interventions such as restrictions on unhealthy food advertising and greater support for using planning regulations to improve local food environments. An energy reduction programme also challenged all food and drink companies, including restaurants and takeaways, to reduce energy by $20 \%$ in a range of everyday foods consumed by children by 2024 with additional recommendations to introduce legislation for consistent energy labelling in the out-of-home sector. More recently, the Chief Medical Officer's independent report on child obesity $^{(7)}$ stated a number of recommendations including fiscal measures to favour healthier options such as energy caps on food and drink sold outside the home, nutrition labelling and free drinking water to be available for all customers in on-site premises. Emphasising that there is a clear need to consider the role of the food environment and the nutritional value of food and beverages consumed outside the home in relation to childhood obesity.

These studies show that there is a trend for families and young children to eat increasingly frequently outside of the home. This is not to say that families should not enjoy an occasional treat; however, we need to recognise that if opting to eat out on a more regular basis, then the nutritional content of the food served in restaurants can make significant contributions to the overall diet. Changing the occasional restaurant meal to a healthier one may not have a great impact on obesity risk ${ }^{(27)}$; however, it should be easier to eat out healthily and be possible, even sustainable, to eat in restaurants as part of an overall healthy diet ${ }^{(19,28)}$. Furthermore, it is recognised that children's menus in restaurants are just one component of the complex problem that is obesity, and thus only an innovative and multifaceted $\operatorname{approach}^{(29,30)}$ that includes policy changes ${ }^{(31)}$, transformation of the food supply ${ }^{(32,33)}$ as well as changes to the environment will solve. 


\section{Acknowledgements}

Financial support: This research received no specific grant from any funding agency, commercial or not-for-profit sectors. Conflict of interest: None. Authorship: S.R. is the sole contributor of this commentary. Ethics of human subject participation: Not applicable.

\section{References}

1. Public Health England (2017) Health matters: obesity and the food environment. https://www.gov.uk/government/ publications/health-matters-obesity-and-the-food-environment/ health-matters-obesity-and-the-food-environment- 2 \#improvingeveryones-access-to-healthier-food-choices (accessed December 2019).

2. Centers for Disease Control and Prevention (2018) Percentage of youths aged 2-19 years consuming any fast food on a given day, by race and Hispanic origin National Health and Nutrition Examination Survey, 20132016. MMWR Morb Mortal Wkly Rep 67, 1134. doi: 10.15585/ mmwr.mm6740a8.

3. Seguin RA, Aggarwal A, Vermeylen F et al. (2016) Consumption frequency of foods away from home linked with higher body mass index and lower fruit a vegetable intake among adults: a cross-sectional survey. J Envrion Public Health 2016, 3074241 doi: 10.1155/2016/3074241.

4. Paddock J, Warde A, Whillans J (2017) The changing meaning of eating out in three English cities 1995-2015. Appetite 119, $5-13$.

5. Non-Communicable Disease Risk Factor Collaboration (2017) Worldwide trends in body mass index, underweight, overweight, and obesity from 1975 to 2016: a pooled analysis of 2416 population-based measurement studies in 128.9 million children, adolescents, and adults. Lancet 390, 2627-2642.

6. Public Health England (2017) National Child Measurement Programme - England 2016-17. http://digital.nhs.uk/catalogue/ PUB30113 (accessed March 2018).

7. Chief Medical Officer (2019) Time to solve childhood obesity. An independent report. https://assets.publishing.service. gov.uk/government/uploads/system/uploads/attachment_ data/file/837907/cmo-special-report-childhood-obesityoctober-2019.pdf (accessed December 2019).

8. Dunn C G, Vercammen KA, Frelier J M, et al. (2020) Nutrition composition of children's meals in 26 large U.S. chain restaurants. Pub Health Nutr 23, 2245-2252.

9. Young M, Coppinger T \& Reeves S (2019) The nutritional value of children's menus in chain restaurants in the United Kingdom and Ireland. J Nutr Educ Behav 51, 817-825.

10. Webley K (2010) A brief history of the happy meal. Time, 30 April 2010.

11. Cohen DA \& Lesser LI (2016) Obesity prevention at the point of purchase, Ob Rev 17, 389-396.

12. Henry HKM \& Borzekowski DLG (2015) Well, that's what came with it. A qualitative study of U.S. mothers' perceptions of healthier default options for children's meals at fast-food restaurants. Appetite 87, 108-115.

13. Sharpe KM \& Staelin R (2010) Consumption effects of bundling: consumer perceptions, firm actions and public policy implications, J Pub Policy Market 29, 170-188.

14. Harris J \& Thomas VL (2016) The influence of bundling and caloric knowledge on calories ordered and purchase intent. J Consum Aff 51, 113-132.
15. Loeb KL, Radnitz C, Keller K et al. (2017) The application of defaults to optimise parents' health-based choices for children. Appetite 113, 368-375.

16. Fisher JO, Roll B \& Birch LL (2003) Children bite size and intake of an entrée are greater with large portions than the age-appropriate or self-selected portions. Am J Clin Nutr 77, 1164-1170.

17. Cantor J, Breck A \& Elbel B (2016) Correlates of sugarsweetened beverages purchased for children at fast food restaurants. Am J Pub Health 106, 2038-2041.

18. Anzman-Frasca S, Dawes F, Silwa S et al., (2014) Healthier side dishes at restaurants: an analysis of children's perspectives, menu content and energy impacts, Int J Behav Nutr Phys Act 11, 18. doi:10.1186/1479-5868-11-81.

19. Brindal E, Mohr P, Wilson C et al. (2008) Obesity and the effects of choice at a fast food restaurant. Obes Res Clin Prac 2, 111-117.

20. Anzman-Frasca S, Folta SC, Glenn ME et al. (2017). Healthier children's meals in restaurants: an exploratory study to inform approaches that are acceptable across stakeholders. J Nutr Educ Behav 49, 285-295.

21. Anzman-Frasa S, Mueller MP, Silwa S et al. (2015) Changes in children's meal orders following healthy menu modifications at a regional US restaurant chain. Ped Obes $\mathbf{2 3}$, $1055-1062$.

22. Hay B (2017) Why do kids' menus always have chicken nuggets? Childrens observations on the provision of food in hotels on family holidays. Hospit Soc 8, 69-96.

23. Schneider S, Hilger-Kolb J \& Rusing Lisa (2019) Obesity a la carte? Children's meal options in German full-service restaurants. Public Health Nutr 23, 102-111. doi: 10. 1017/S1368980019002398.

24. Reeves S, Wake Y \& Zick A (2011) Nutrition Labelling and portion size Information on children's menus in fast-food and table-service chain restaurants in London, UK. $J$ Nutr Educ Behav 43, 543-547

25. Goffe L, Rushton S, White M et al. (2017) Relationship between mean daily energy intake and frequency of consumption of out-of-home meals in the UK National Diet and Nutrition Survey. Int J Behav Nutr Phys Act 14. doi:10. 1186/s12966-017-0589-5.

26. Department of Health and Social Care (2016) Childhood Obesity: A Plan for Action, Chapter 2. HM Government. https://assets.publishing.service.gov.uk/government/uploads/ system/uploads/attachment_data/file/718903/childhoodobesity-a-plan-for-action-chapter-2.pdf (accessed December 2019).

27. Mazidi M \& Speakman JR (2017) Higher densities of fast-food and full-service restaurants are not associated with obesity prevalence. Am J Clin Nutr, 106, 603-613.

28. Gorski MT \& Roberto CA (2015) Public health policies to encourage healthy eating habits: recent perspectives. $J$ Healthcare Leader 7, 81-90.

29. Kaur A \& Briggs ADM (2019) Calorie labelling to reduce obesity. BMJ 367, 16119.

30. Economos C (2019) Designing effective and sustainable multifaceted interventions for obesity prevention and healthy communities. Obesity 25, 1155-1156.

31. Frieden TR, Dietz W \& Collins J (2010) Reducing childhood obesity through policy change: acting now to prevent obesity. Health Affairs 29, 357-363. doi: 10.1377/hlthaff.2010.0039.

32. Jebb SA (2011) Calorie labelling on the high street. BMJ 343, d4502.

33. Branca F, Laertey A, Oenema S, et al. (2019) Transforming the food system to fight non-communicable disease. BMJ 364, 1296. 